\title{
GAME-THEORETIC APPROACH TO TOURISM SUPPLY CHAIN COORDINATION UNDER DEMAND UNCERTAINTY FOR PACKAGE HOLIDAYS
}

\section{XINYAN ZHANG,* HAIYAN SONG, $\dagger$ GEORGE Q. HUANG, $\ddagger$ and WANLI CHEN $\dagger$}

*School of Professional and Executive Education Development, The Hong Kong Polytechnic University, Kowloon, Hong Kong

$†$ School of Hotel and Tourism Management, The Hong Kong Polytechnic University, Hung Hom, Kowloon, Hong Kong

$\ddagger$ Department of Industrial and Manufacturing Systems Engineering, The University of Hong Kong, Pokfulam Road, Hong Kong

\begin{abstract}
Demand uncertainty is one of the most significant characteristics of the tourism industry. In a typical tourism supply chain (TSC) for package holidays, multiple tour operators reserve rooms from a hotel chain in advance according to their demand predictions. Discrepancies between demand predictions and actual demand lead to shortages or unused room reservations, which inevitably leads to reduced profits for the tour operators concerned. This article examines different TSC coordination strategies to determine how they can be used to help alleviate such negative effects. A game-theoretic approach is used to analyze the different coordination relationships between TSC players. Two coordination programs are discussed. The first is a horizontal coordination program in which tour operators exchange shortages or unused reservations with each other. The second is a vertical coordination program in which tour operators trade shortages or unused reservations with hotel chains. Game models are established and analyzed for the two coordination strategies and uncoordinated conditions, respectively. The analytical results suggest that both coordination strategies can be used to reduce the negative impacts of the demand uncertainty. The results also show that the horizontal coordination is preferred to the vertical coordination when the competition among tour operators is fierce.
\end{abstract}

Key words: Tourism supply chain; Game theory; Supply chain coordination; Demand uncertainty; Package holidays

\section{Introduction}

Although independent travel has become increasingly attractive to younger generations over the past decade, package holidays are still the most popular form of tourism. Package holidays are configured from a variety of service providers such as enterprises that offer accommodation, transportation, and excursions, which together form the so-called tourism supply chain (TSC) 
discussed in this article. A schematic diagram of a typical TSC for package holidays at a certain destination is shown in Figure 1. As the customers at the downstream end of a TSC, tourists purchase package holidays from travel agents. Tour operators organize a series of activities as package holiday products for travel agents (Budeanu, 2005; Tapper \& Font, 2007). Travel agents and tour operators can be housed within the same or separate business entities. Services provided by midstream enterprises, such as theme parks, shopping centers, hotels, and transportation operators, are amalgamated by tour operators. Further upstream, enterprises provide raw materials and services to midstream TSC enterprises.

Uncertainty about future demand is one of the most significant characteristics of the tourism industry (Gómez \& Sinclair, 1991). A number of factors, both internal and external, can result in uncertainty over the level of demand for package holidays. For example, excessive advertising of package holidays may cause overbooking and lead to a supply shortage. Another uncertainty associated with package holidays is seasonality.

It is beyond dispute that demand uncertainty will lead to significant losses for business entities involved in a TSC. Researchers believe that an appropriate strategy of supply chain coordination can help to mitigate the negative effects of demand uncertainty. Coordination is a pattern of decision making and communication among a set of actors who perform tasks to achieve goals (Malone, 1987). Accordingly, supply chain coordination can be regarded as a pattern of decision making and communication among supply chain participants who perform tasks to achieve common goals (e.g., maximizing supply chain profit).

A TSC consisting of multiple tour operators and accommodation providers (i.e., hotels) involves two different types of coordination program. The first occurs when tour operators reserve too many rooms and cannot fill their reservations,

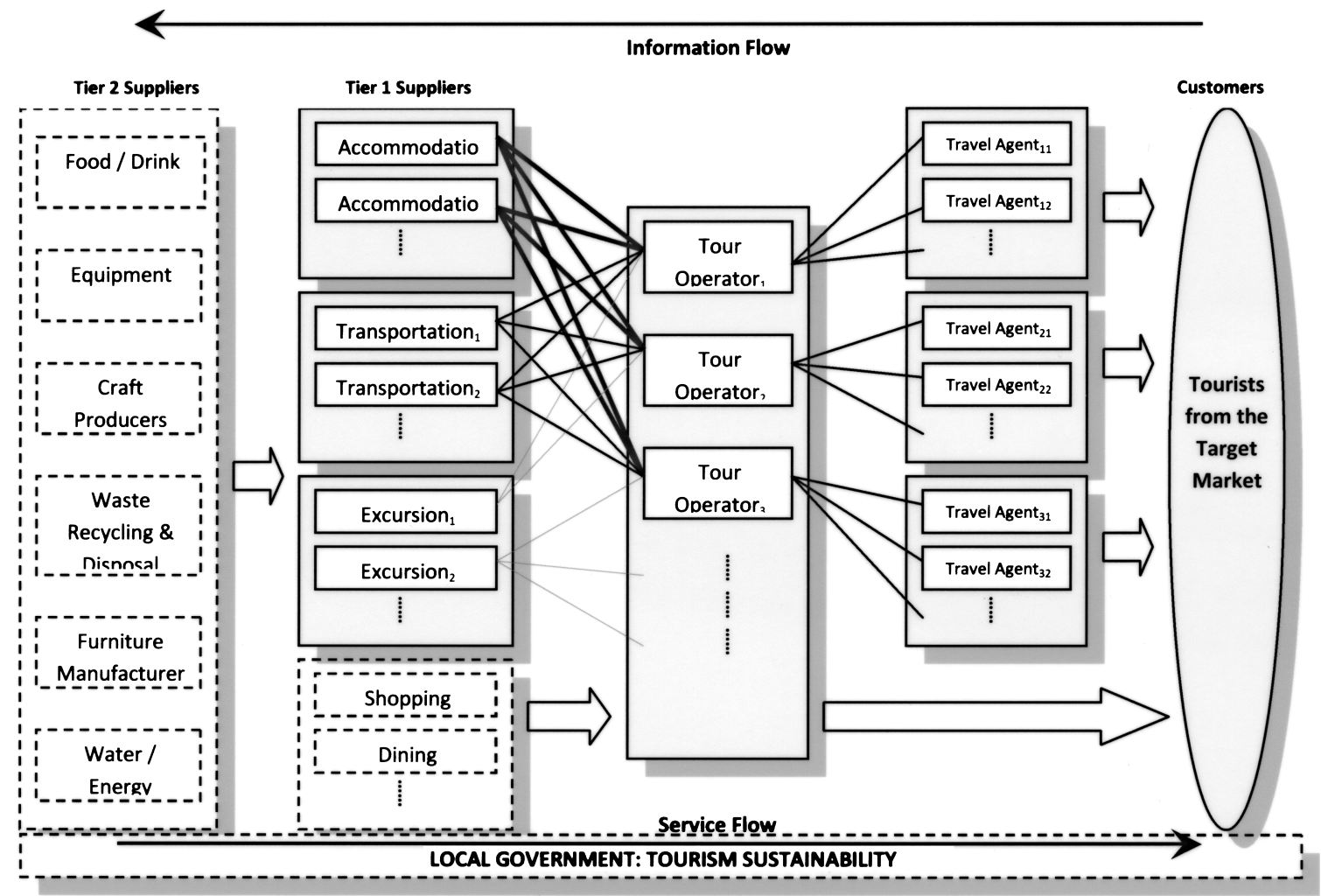

Figure 1. A typical TSC at a destination. Adapted from Zhang et al. (2009). 
in which case they may transfer overbookings to those who have made insufficient reservations. In this study, we call such programs horizontal coordination within a TSC. In general, these programs involve the coordination of homogeneous participants at the same echelon of a TSC.

The second type of coordination program occurs when tour operators that have reserved too many (or too few) hotel rooms consider returning (or repurchasing) overbooked (or underbooked) rooms to (or from) hotels. We argue that tour operators do not choose to offset their losses by increasing their room rates. If they do so, sales of package tours would fall and the reputations of TSC players would be damaged. Therefore, tour operators are likely to limit themselves to two choices: returning overbooked rooms or repurchasing hotel rooms to cover a shortage. In this study, we refer to this practice as the vertical coordination of a TSC. In general, it involves heterogeneous participants at different echelons of a TSC.

A large number of previous analyses have been carried out on supply chain coordination strategies, with a particular focus on the manufacturing industry. To the best of our knowledge, no in-depth analytical research on coordination strategies related to the tourism industry has been carried out. There has been a particular lack of analysis using game-theoretic approaches, although the effectiveness of game theory in studying manufacturing supply chain coordination has been proven (Parlar \& Wang, 1994; Rosenblatt \& Lee, 1985; Viswanathan \& Wang, 2003; Wang, 2002). The main objective of this article is to use a game-theoretic approach to examine the effects of different coordination strategies used in TSCs for package holidays. As described above, the TSC studied in this article consists of multiple tour operators and hotels. Hotels form chains to maintain their competitiveness in terms of occupancy rate (Aguiló, Alegre, $\&$ Sard, 2002). The use of both horizontal and vertical coordination programs in the TSC is examined. Specifically, in the horizontal coordination program, tour operators with a lower level of demand for their products exchange extra rooms with tour operators that have a higher level of demand at a contractual exchange price. In the vertical coordination program, tour operators repurchase rooms from hotel chains to cover shortages or re- turn unused reservations to hotel chains when they have overbooked. Game models are established for the conditions of noncoordination, horizontal coordination, and vertical coordination, respectively. The models are then analyzed to find an optimal equilibrium for each condition. We subsequently compare the two coordination models to establish which is more efficient in mitigating the negative effects of demand uncertainty. The TSC and the different TSC coordination programs studied and compared in this article are illustrated in Figure 2.

The rest of this article is organized as follows. In the next section, the essential literature relevant to this study is reviewed. The following section formulates game models for the cases of noncoordination, horizontal coordination, and vertical coordination, respectively. Game equilibria are also analyzed. In the fourth section, we derive some useful managerial implications from the equilibria of the game models by means of comparison. Our general conclusions and the limitations of this study are discussed in the last section.

\section{Literature Review}

Capacity exchange mechanisms can be used to smooth demand uncertainty (Hogendorn, 2006). In this article, this type of mechanism is employed to examine equilibrium solutions to the reservation capacities of tour operators in TSCs, as well as to argue that the net profits tour operators can expect to make under capacity exchange conditions are higher than those they can expect to make under conditions of nonexchange.

The literature relevant to this study can be divided into research on TSCs for package holidays, studies on the application of game theory to the tourism industry, and the literature on demand uncertainty problems.

The profile of the TSC for package holidays has been discussed by Font, Tapper, Schwartz, and Kornilaki (2008). Both Budeanu (2005) and Tepelus (2005) pointed out that tour operators play a key role in the tourism and hospitality industries. The literature also covers hotel room occupancy (Pan, 2007) and oligopolistic hotel pricing (Baum \& Mudambi, 1995). Buhalis (2000) showed that the main area of competition between hotels and 

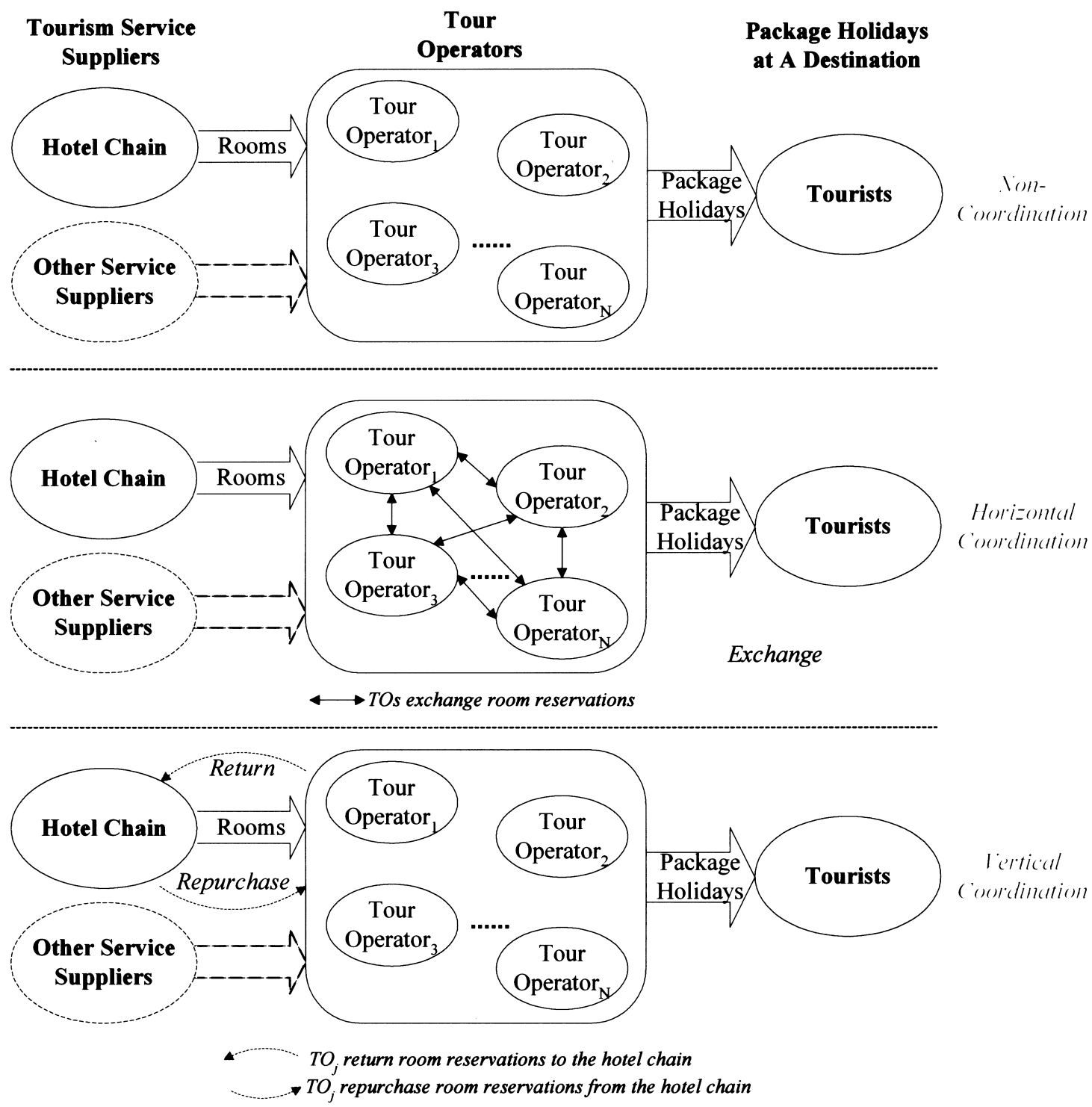

Figure 2. The TSC and the different coordination programs studied in this article.

tour operators centers on profit margins and occupancy rates. Tse (2003) put forward some suggestions on how travel agents should counter hotel disintermediation. R. D. Medina-Muñoz, MedinaMuñoz, and García-Falcón (2003) studied the phenomenon whereby hotels compete with their tour operator partners for a larger share of profits. Wong and Kwan (2001) investigated the competitive strategies of hotels and travel agents and called for cooperation between the two sectors. D.
Medina-Muñoz and García-Falcón (2000) identified the determinants of successful relationships between hotels and travel agents. Theuvsen (2004) claimed that coordination among enterprises can benefit the tourism industry. These studies form the foundation for this study with respect to the discussion on cooperation and competition among tour operators and coordination between tour operators and hotels under demand uncertainty.

Although the use of game-theoretic approaches 
to analyze typical TSC problems is a relatively new research area, it has become increasingly popular in recent years. For example, Taylor (1998) evaluated the strategic pricing behavior of package tour operators by setting up a game-theoretic model. Candela and Cellini (2003) utilized different oligopoly models to investigate tourism development strategies. Wie (2005) developed a noncooperative dynamic game to study strategic capacity investment in the cruise line industry. García and Tugores (2006) explained the rationale for the coexistence of high- and low-quality hotels using a vertical differentiation duopoly model. To the best of our knowledge, demand uncertainty problems that arise in TSCs have not been studied analytically using game-theoretic approaches.

However, demand uncertainty problems have been discussed extensively in other industries. Fisher and Raman (1996) claimed that accurate responses to early sales can reduce the costs resulting from demand uncertainty. Fisher, Hammond, Obermeyer, and Raman (1997) presented a model to quantify the impact of adjusting the levers of demand uncertainty. Marvel and Peck (1995) showed that return policies are helpful in smoothing demand uncertainty. Mantrala and Raman (1999) investigated the impacts of demand variability on buyback and wholesale prices. Return policies have been widely used to moderate the impact of demand uncertainty. By contrast, capacity exchange policies have rarely been applied to deal with such problems. Kwoka (2001) studied exchanges in the automobile industry and noted that competitive concerns over B2B exchanges fall into two broad categories - those involving the final output of the exchange participants (e.g., cars) and those involving the products transacted on the exchanges themselves (e.g., wiring or tires) (pp. 66). Hogendorn (2006) employed a game-theoretic model to compare a capacity exchange strategy with a nonexchange strategy under demand uncertainty. Some studies have also referred to overbooking problems that arise between tour operators and hotels. For example, Hadjinicola and Panayi (1997) argued that hotels should adopt an overbooking policy at either the hotel level or the tour operator level. This article considers the TSC overbooking problem to be a demand shortage problem, and both return policy and capacity ex- change methods are used to smooth the demand shocks in the TSC.

\section{Model Formulation}

We consider a TSC that has $N(N \geq 2)$ tour operators (TO) denoted by the subscript $j=1,2, \ldots$, $N$ and one hotel chain. For simplicity, we assume that each TO provides only one type of package holiday product and that the products provided by different tour operators are imperfectly substitutable. All package holiday products include one night of accommodation provided by the hotel chain. The tour operators reserve rooms in advance with the hotel chain at the same price according to their demand predictions, which are often higher or lower than actual demand due to demand uncertainty. The price per unit of $\mathrm{TO}_{j}$ is $p_{j}$. Following the same approach as that used in Carr and Karmarkar (2005), all of the TOs are assumed to have identical constant marginal cost $c$. $\mathrm{TO}_{j}$ reserves a certain number $\left(k_{j}\right)$ of rooms according to its prediction at a given price $(w)$ and sells package holidays to tourists. We also assume that demand forecasting errors occur due to uncertainties, but that total capacity remains unchanged. Following many other studies (e.g., Hogendorn, 2006), we assume a linear inverse demand function for $\mathrm{TO}_{j}$ as follows:

$$
p_{j}=\alpha-\beta k_{j}-\gamma \sum_{i \neq j} k_{i}+\varepsilon_{j} .
$$

The ratio $\frac{\gamma}{\beta}$ captures the degree of substitution between different package holidays. $\gamma=0$ indicates that the relevant products are independent, and $\gamma=$ $\beta$ indicates that the relevant products are perfect substitutes. In this study, we consider the case where $\alpha>0$ and $0<\gamma<\beta$. In addition, the demand for $\mathrm{TO}_{j}$ includes a random shock $\left(\varepsilon_{j}\right)$, with an expected value of 0 and a constant variance of $\sigma^{2}$. The random shocks affecting different tour operators are not correlated.

In the following subsections, we propose and analyze the game models for the noncoordination, horizontal coordination, and vertical coordination cases, respectively. 


\section{Noncoordination}

In the noncoordination situation, the TSC members studied in this article do not adopt any capacity exchange or return policies. In this case, the linear inverse demand function for $\mathrm{TO}_{j}$ is the same as Equation (1). Therefore, the objective function for $\mathrm{TO}_{j}$ is

$$
\operatorname{Max} \pi_{j}\left(k_{j}\right)=\left(\alpha-\beta k_{j}-\gamma \sum_{i \neq j} k_{i}+\varepsilon_{j}-c\right) k_{j} .
$$

By running a game among the tour operators, we obtain the equilibrium reservation capacity,

$$
k_{j}^{\mathrm{NC}}=\frac{\alpha-c-w}{2 \beta+\gamma(N-1)},
$$

where superscript "NC" stands for the noncoordination situation.

Substituting equation (3) into equation (1), we obtain the expected product price,

$$
E\left(p_{j}^{\mathrm{NC}}\right)=\frac{\beta \alpha+[\beta+\gamma(N-1)](c+w)}{2 \beta+\gamma(N-1)} .
$$

At equilibrium, the expected net profit of each TO is

$$
E\left(\pi_{j}^{\mathrm{NC}}\right)=\frac{\beta(\alpha-c-w)^{2}}{[2 \beta+\gamma(N-1)]^{2}} .
$$

\section{Horizontal Coordination}

In the horizontal coordination case, we assume that if $\mathrm{TO}_{j}$ needs $\delta_{j}$, additional rooms on top of those it has reserved, it buys enough rooms to cover the shortage from the other TOs at exchange price $s$; if it has $\delta j$ unused rooms, then it sells them at price. Therefore, the linear inverse demand function for $\mathrm{TO}_{j}$ can be written as

$$
p_{j}=\alpha-\beta\left(k_{j}+\delta_{j}\right)-\gamma \sum_{i \neq j}\left(k_{i}+\delta_{i}\right)+\varepsilon_{j} .
$$

The objective function for $\mathrm{TO}_{j}$ is

$$
\operatorname{Max} \pi_{j}\left(k_{j}, s\right)=\left(p_{j}-c\right)\left(k_{j}+\delta j\right)-w k_{j}-s \delta_{j}
$$

To maximize $\pi_{j}$, the exchange capacity of $\mathrm{TO}_{j}$ is (note that remains unchanged)

$$
\delta_{j}=\frac{\alpha-\gamma \sum_{i=1}^{N} k_{i}-s-c+\varepsilon_{j}}{2(\beta-\gamma)}-k_{j} .
$$

The total amount of capacity sold in the exchange must be equal to the total amount purchased; hence, $\sum_{i=1}^{N} \delta=0$. Combining this condition, we obtain the equilibrium exchange price,

$$
s^{*}=\alpha-c-[2 \beta+\gamma(N-2)] \frac{\sum_{i=1}^{N} k_{i}}{N}+\bar{\varepsilon},
$$

where $\bar{\varepsilon}=\left(\sum_{i=1}^{N} \varepsilon_{i}\right) / N$.

Substituting equation (9) into equation (8), we have

$$
\delta_{j}\left(s^{*}\right)=\bar{k}-k_{j}+\frac{\varepsilon_{j}-\bar{\varepsilon}}{2(\beta-\gamma)},
$$

where $\bar{k}=\left(\sum_{i=}^{N} k_{i}\right) / N$.

In particular, we have $E\left(\varepsilon_{j}\right)=0, E\left(\varepsilon_{i} \varepsilon_{j}\right)=0 \forall i \neq$ $j$, and $E\left(\varepsilon_{j}^{2}\right)=\sigma^{2}$. Therefore, the expected net profit of $\mathrm{TO}_{j}$ is

$$
\begin{aligned}
E\left(\pi_{j}\right)= & (\beta-\gamma)(\bar{k})^{2}+[\alpha-(2 \beta+\gamma N-2 \gamma) \bar{k} \\
& -c-w] k_{j}+\frac{(N-1) \phi^{2}}{4(\beta-\gamma) N} .
\end{aligned}
$$

Solving $\frac{\partial E\left(\pi_{j}\right)}{\partial k_{j}}=0$ leads to the following equilibrium reservation capacity of $\mathrm{TO}_{j}$.

$$
k_{j}^{\mathrm{HC}}=\frac{\alpha-c-w}{2 \beta+\gamma(N-1)},
$$

where the superscript HC stands for horizontal coordination.

Substituting equation (11) into equation (6), we obtain the expected product price, 


$$
E\left(p_{j}^{\mathrm{HC}}\right)=\frac{\beta \alpha+[\beta+\gamma(N-1)](c+w)}{2 \beta+\gamma(N-1)} .
$$

Substituting equation (11) into equation (10), we arrive at the expected net profit of $\mathrm{TO}_{j}$ :

$$
E\left(\pi_{j}^{\mathrm{HC}}\right)=\frac{\beta(\alpha-c-w)^{2}}{[2 \beta+\gamma(N-1)]^{2}}+\frac{(N-1) \sigma^{2}}{4(\beta-\gamma) N} .
$$

\section{Vertical Coordination}

In the vertical coordination case, we assume that if $\mathrm{TO}_{j}$ needs more rooms $\left(\theta_{j}\right)$ than it has reserved $\left(k_{j}\right)$, it repurchases enough rooms to cover the shortage from the hotel chain at a trading price $\left(r_{1}\right)$; if it has unused rooms $\left(\theta_{j}\right)$, then it returns them to the hotel chain at price $r_{2}$. In this situation, we assume that $r_{1}=w+\Delta$ and $r_{2}=w-\Delta(w$ is the wholesale price and $\Delta$ is the deposit fee, which is a constant). This means that the tour operators will repurchase rooms to cover any room shortage at a higher price and lose any deposit for overbooking.

From equation (1) and the above assumption, the demand function for $\mathrm{TO}_{j}$ is

$$
p_{j}=\alpha-\beta\left(k_{j}+\theta_{j}\right)-\gamma \sum_{i \neq j}\left(k_{i}+\theta_{i}\right)+\varepsilon_{j} .
$$

The objective function for $\mathrm{TO}_{j}$ is

$$
\operatorname{Max} \pi_{j}\left(k_{j}\right)=\left(p_{j}-c-w\right)\left(k_{j}+\theta_{j}\right)-\Delta\left|\theta_{j}\right|
$$

To maximize $\pi_{j}, \mathrm{TO}_{j}$ reserves the room capacity,

$$
k_{j}=\frac{\alpha-\gamma \sum_{i=1}^{N} k_{i}-c-w+\varepsilon_{j}}{2 \beta-\gamma}-\theta_{j} .
$$

Solving equation (16) leads to the following Cournot equilibrium for $\mathrm{TO}_{j}$ :

$$
\begin{aligned}
k_{j}= & \frac{\alpha-c-w+\varepsilon_{j}}{2 \beta-\gamma} \\
& -\frac{\gamma N(\alpha-c-w+\bar{\varepsilon})-\gamma(2 \beta-\gamma) \sum_{i=1}^{N} \theta_{i}}{(2 \beta-\gamma)[2 \beta+\gamma(N-1)]}-\theta_{j} .
\end{aligned}
$$

[The derivation of equation (17) is available from the corresponding author upon request.]
The total amount of capacity purchased on the market is equal to the total amount returned, which means $\sum_{i=1}^{N} \theta_{i}=0$. Combining this condition, we obtain the equilibrium reservation capacity for $\mathrm{TO}_{j}$ :

$$
\begin{aligned}
k_{j}= & \frac{\alpha-c-w+\varepsilon_{j}}{2 \beta-\gamma} \\
& -\frac{\gamma N(\alpha-c-w+\bar{\varepsilon})}{(2 \beta-\gamma)[2 \beta+\gamma(N-1)]}-\theta_{j} .
\end{aligned}
$$

Therefore, the expected product price and the expected net profit for $\mathrm{TO}_{j}$ are

$$
E\left(p_{j}^{\mathrm{vC}}\right)=\frac{\beta \alpha+[\beta+\gamma(N-1)](c+w)}{2 \beta+\gamma(N-1)}
$$

and

$$
\begin{aligned}
E\left(\pi_{j}^{\mathrm{VC}}\right)= & \frac{\beta(\alpha-c-w)^{2}}{[2 \beta+\gamma(N-1)]^{2}} \\
& +\frac{\beta\left[(2 \beta+\gamma N)^{2}-3 \gamma^{2}(N-1)\right] \sigma^{2}}{(2 \beta-\gamma)^{2}[2 \beta+\gamma(N-1)]^{2}}-\Delta\left|\theta_{j}\right|,
\end{aligned}
$$

where the superscript VC stands for vertical coordination.

\section{A Comparative Analysis of the Different Coordination Models}

In this section, we derive some useful managerial implications by comparing the results from the game models described above. We first compare the results from the models for noncoordination, horizontal coordination, and vertical coordination with a view to investigating how coordination can reduce demand uncertainty and the impact of coordination strategy on optimal TSC decisions. We then compare the results from the horizontal and vertical coordination cases to establish which model is more effective in reducing demand uncertainty.

\section{Coordination and Noncoordination}

Horizontal Coordination and Noncoordination. Firstly, from equations (3) and (11), we have 
$k^{\mathrm{HC}}=\frac{\gamma-c-w}{2 \beta+\gamma(N-1)}=k^{\mathrm{NC}}$, which leads to the following theorem.

Theorem 1: Horizontal coordination does not impact the level of tour operators' reservations.

This theorem indicates that tour operators do not need to change their reservation decisions, regardless of whether they choose to coordinate with each other. The theorem implies that horizontal coordination will not result in additional costs for the tour operators concerned.

Secondly, comparing equations (4) and (12), we can see that the expected product price for individual tour operators in the horizontal coordination case is the same as the price in the noncoordination case. This leads to Theorem 2 .

Theorem 2: Horizontal coordination does not change the price of package holidays.

This theorem implies that the decision makers within the tour operators concerned are unable to change their pricing strategies in the horizontal coordination case.

Thirdly, from equations (5) and (13), we have:

$$
E\left(\pi_{j}^{\mathrm{HC}}\right)-E\left(\pi_{j}^{\mathrm{NC}}\right)=\frac{(N-1) \sigma^{2}}{4(\beta-\gamma) N} .
$$

Bear in mind that the number of tour operators is $N>1$ and that the degree of substitution of package holidays is $0<\gamma / \beta<1$. Therefore, equation (20) implies Theorem 3.

Theorem 3: A horizontal coordination strategy is more effective for dealing with demand shocks for tour operators.

Analyzing equation (20), we also obtain the following three propositions.

Proposition 1: When the variance of a random shock is larger, horizontal coordination becomes more beneficial.

This proposition indicates that when demand uncertainty increases, the benefits of horizontal coordination for individual tour operators also increase.

Proposition 2: When more tour operators enter the market, horizontal coordination is more beneficial than noncoordination both to individual tour operators and to the industry as a whole, although the homogeneous profits of individual tour operators decrease under both horizontal coordination and noncoordination conditions. (The derivation of Proposition 2 is available from the corresponding author upon request.)

Proposition 3: When the degree of substitution $(\gamma /$ $\beta$ ) of package holidays increases (or the level of differentiation among products decreases), horizontal coordination becomes more beneficial than noncoordination, although the homogeneous profits of individual tour operators decrease under both horizontal coordination and noncoordination conditions. (The derivation of Proposition 3 is available from the corresponding author upon request.)

When the degree of substitution of package holidays increases or the level of differentiation among products decreases, competition between tour operators intensifies. In other words, the above proposition implies that in a fiercely competitive tourism market, tour operators prefer to establish coordination relationships with each other.

Vertical Coordination and Noncoordination. A comparison of the results obtained under the respective conditions of noncoordination and vertical coordination shows that the equilibrium product price charged by individual tour operators is the same in both cases. In other words, the following theorem holds.

Theorem 4: Vertical coordination between tour operators and hotel chains does not change the price of package holidays.

We also find that the impact of demand shocks on tour operators' profits in the vertical coordination case are related to the scale of individual tour operators, the degree of substitution of package holidays, the size of the deposit, and exchange capacity.

\section{A Comparison Between Horizontal and Vertical Coordination}

Rewriting equations (13) and (19) here reminds us of the net profit expected under horizontal coordination, 


$$
E\left(\pi_{j}^{\mathrm{HC}}\right)=\frac{\beta(\alpha-c-w)^{2}}{[2 \beta+\gamma(N-1)]^{2}}+\frac{(N-1) \sigma^{2}}{4(\beta-\gamma) N},
$$

and the net profit expected under vertical coordination,

$$
\begin{aligned}
E\left(\pi_{j}^{\mathrm{VC}}\right)= & \frac{\beta(\alpha-c-w)^{2}}{[2 \beta+\gamma(N-1)]^{2}} \\
& +\frac{\beta\left[(2 \beta+\gamma N)^{2}-3 \gamma^{2}(N-1)\right] \sigma^{2}}{(2 \beta-\gamma)^{2}[2 \beta+\gamma(N-1)]^{2}}-\Delta\left|\theta^{j}\right| .
\end{aligned}
$$

In the following discussion, we ignore the deposit losses in the above equation. (The deposit losses have a negative impact on the expected profits of individual tour operators under vertical coordination. In this article, we first ignore the deposit losses, which lead to inflated profits for individual tour operators under vertical coordination. If the inflated profits under vertical coordination are still smaller than the expected profits of individual tour operators under horizontal coordination, we can compare the two coordination cases without taking deposit losses into account.) Here, we can compare the net profits under horizontal and vertical coordination conditions by comparing $u=\frac{(N-1) \sigma^{2}}{4(\beta-\gamma) N} \quad$ with $v=\frac{\beta\left[(2 \beta+\gamma N)^{2}-3 \gamma^{2}(N-1)\right] \sigma^{2}}{(2 \beta-\gamma)^{2}[2 \beta+\gamma(N-1)]^{2}}$. To compare $u$ and $v$, we define

$$
f=\frac{u}{v}=\frac{(N-1)(2 \beta-\gamma)^{2}[2 \beta+\gamma(N-1)]^{2}}{\left.4 N \beta(\beta-\gamma)[2 \beta+\gamma N)^{2}-3 \gamma^{2}(N-1)\right]} .
$$

If $f>1$, then $u>v$; if $f<1$, then $u=v$; if $f=1$, then $u=v$. Dividing the numerator and the denominator of $f$ by $\beta^{4}$ and letting $x=\gamma / \beta(0<x<1)$, we obtain

$$
f=\frac{(N-1)(2-x)^{2}[2+x(N-1)]^{2}}{\left.4 N(1-x)[2+x N)^{2}-3 x^{2}(N-1)\right]} .
$$

Let $F$ denote the difference between the numerator and the denominator of $f$, giving us

$$
\begin{aligned}
F= & (N-1)(2-x)^{2}[2+x(N-1)]^{2} \\
& -4 N(1-x)\left[(2+x N)^{2}-3 x^{2}(N-1)\right] .
\end{aligned}
$$

We can see that two variables, $x$ and $N$, can affect the value of $F$. First considering $F$ as a function of $x$, we find that $F(x)$ has only one root (we call it $x_{1}$ ), where $x_{1} \in(0,1)$ (the derivation of this result is available from the corresponding author upon request), and when $x>x_{1}, F(x)>0$. Because $x$ denotes the degree of substitution of package holiday products, we obtain the following theorem.

Theorem 5: When the degree of substitution of package holidays is high, horizontal coordination is more beneficial in smoothing demand shocks than vertical coordination.

As a decrease in the level of differentiation among products leads to more intense competition between tour operators, the above theorem indicates that under conditions of fierce competition, tour operators prefer to establish a horizontal coordination relationship with each other.

We now present a numerical example of $F(x)$. The simulative curve for $F(x)$ when there are six tour operators in the market $(N=6)$ is shown in Figure 3..

From Figure 3, we can see that when the degree of substitution of package holidays, for example, $x$, is less than 0.62 , vertical coordination is more beneficial than horizontal coordination. The difference between the two coordination schemes is an increase function of $x$ when $x$ is less than 0.26 and is a decreasing function of $x$ when $x$ is greater than 0.38 . The difference is not sensitive when $x$ is between 0.26 and 0.38 . On the other hand, when $x$ is greater than 0.62 , horizontal coordination is more beneficial than vertical coordination. The difference between the two coordination schemes is an increase function of $x$.

Now let us consider $F$ as a function of $N$. We find that when $0<x<0.8925, F(N)$ has only one root $n$ (the derivation of this result is available from the corresponding author upon request).

Proposition 4: The entry of new tour operators may make horizontal coordination more profitable than vertical coordination both to individual tour operators and to the industry as a whole when the degree of substitution of package holidays is sufficiently low.

This proposition implies that an expansion in the size of the industry increases the intensity of 
competition. Therefore, incumbent firms are likely to prefer the strategy of exchanging their shortages/unused capacity with each other to reduce demand shocks.

If we assume $x=0.5$ and $3 \leq N \leq 17$, then the following example shows the numerical path for $F(N)$.

From Figure 4, we can see that when $x=0.5$ and $3 \leq N \leq 9, F(N)<0$. This means that under such conditions, vertical coordination is more beneficial than horizontal coordination. However, when $N$ increases to above 9 , the results show that this trend reverses. That is, when the number of tour operators in the market increases, horizontal coordination is more beneficial than vertical coordination.

\section{Concluding Remarks}

This article uses a game-theoretic approach to investigate the effects of two different coordination strategies on a TSC for package holidays under conditions of uncertain demand. The first strategy is a horizontal coordination in which tour operators exchange their shortages/unused reser- vations with a hotel chain. The second strategy involves vertical coordination in which tour operators repurchase/return rooms to cover any shortages/ unused reservations from/to their supplier (e.g., a hotel chain). Game models are established both for the two coordination cases and for the noncoordination case.

Equilibrium solutions are derived and compared to generate managerial implications. One of the general conclusions of the study is that both coordination strategies can be used to smooth out demand uncertainties and enable TSC players to achieve better results. We also find that horizontal coordination does not affect either the level of tour operators' reservations or the price of package holidays. When more tour operators enter the market or product differentiation decreases, we find that the horizontal coordination is preferred to the vertical coordination.

One potential limitation of this study is that we have assumed market demand for package holidays is constant overtime. This assumption may be too restrictive. For instance, extremely bad weather or a disaster at the relevant destination

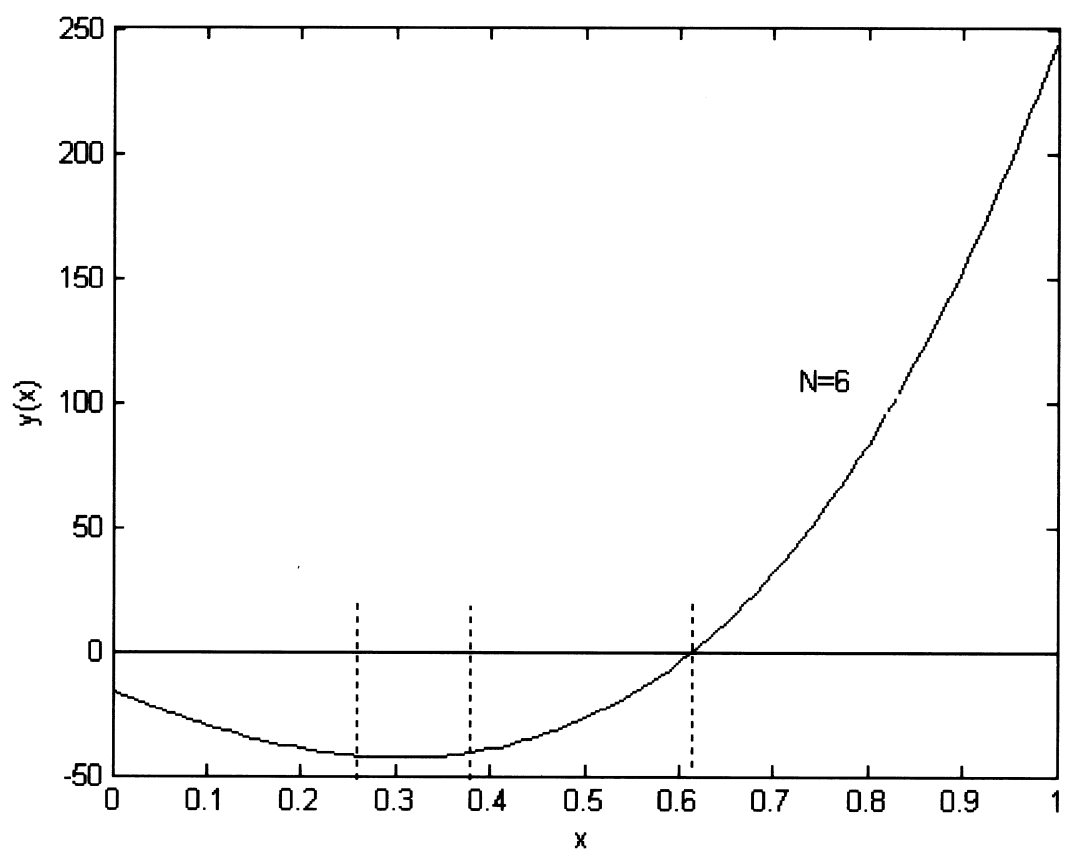

Figure 3. The simulative curve of $F(x)$ when $N=6$. 


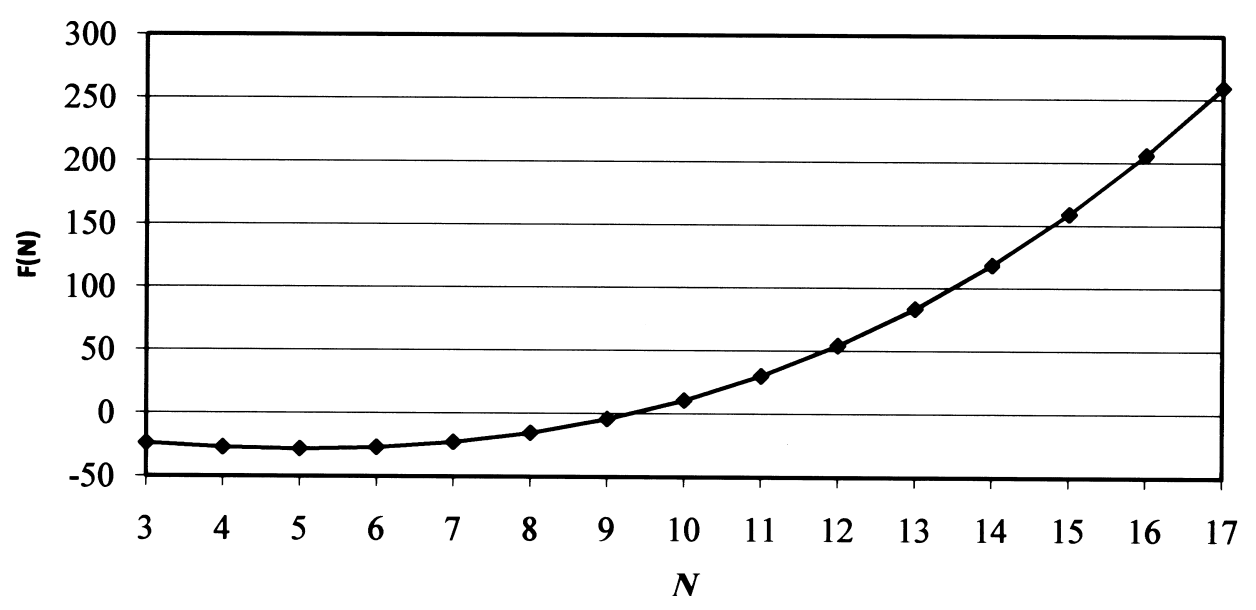

Figure 4. Numerical results of a comparison between the horizontal and vertical coordination models $(x=0.5$ and $3 \leq N \leq 17)$.

may drastically reduce total market demand for package holidays at the destination. The game models presented in this study may not be able to deal with such drastic changes. The dynamic game-theoretic models are likely to be more appropriate in such situations. Another limitation of this study is that we have assumed that all the hotels in a hotel chain charge a uniform room rate. In practice, tour operators can repurchase/return rooms to cover any shortages/unused reservations from/to alternative hotels that are part of a chain at different prices. This factor indicates that more complex game models are required to account for the competition between alternative hotels in the same chain.

\section{Acknowledgment}

Financial support of The Hong Kong Polytechnic University (Grant No. GU743) is acknowledged.

\section{References}

Aguiló, E., Alegre, J., \& Sard, M. (2002). Analysis of package holiday prices in the Balearic Islands (Working Paper No. 40). Illes Balears, Spain: Universitat de les Illes Balears.

Baum, T., \& Mudambi, R. (1995). An empirical analysis of oligopolistic hotel pricing. Annals of Tourism Research, 22(3), 501-516.

Budeanu, A. (2005). Impacts and responsibilities for sustainable tourism: A tour operator's perspective. Journal of Cleaner Production, 13(2), 89-97.
Buhalis, D. (2000). Relationships in the distribution channel of tourism: Conflicts between hoteliers and tour operators in the Mediterranean region. International Journal of Hospitality \& Tourism Administration, 1(1), 113-139.

Candela, G., \& Cellini, R. (2003, September). Investment in the tourism market: A dynamic model of differentiated oligopoly. Paper presented at the International Conference on Tourism and Sustainable Economic Development Conference: Macro and Micro Economic Issues. Chia, Sardinia, Italy.

Carr, S. M., \& Karmarkar, U. S. (2005). Competition in multi-echelon assembly supply chains. Management Science, 51(1), 45-59.

Fisher, M., Hammond, J., Obermeyer, W., \& Raman, A. (1997). Configuring a supply chain to reduce the cost of demand uncertainty. Production and Operations Management, 6(3), 211-225.

Fisher, M., \& Raman, A. (1996). Reducing the cost of demand uncertainty through accurate response to early sales. Operations Research, 44(1), 87-99.

Font, X., Tapper, R., Schwartz, K., \& Kornilaki, M. (2008). Sustainable supply chain management in tourism. Business Strategy and the Environment, 17, 260-171.

García, D., \& Tugores, M. (2006). Optimal choice of quality in hotel services. Annals of Tourism Research, 33(2), 456-469.

Gómez, V. B., \& Sinclair, M. T. (1991). Integration in the tourism industry: A case study approach. In M. T. Sinclair \& M. J. Stabler (Eds.), The tourism industry: An international analysis (pp. 67-90). Wallingford, UK: CAB International.

Hadjinicola, G. C., \& Panayi, C. (1997). The overbooking problem in hotels with multiple tour operators. International Journal of Operations \& Production Management, 17(9), 874-885. 
Hogendorn, C. (2006). Tacit collusion in capacity investment: The role of capacity exchange (Working Paper No. 2006-002). Middletown, CT: Wesleyan University.

Kwoka, J. E. (2001). Automobiles: The old economy collides with the new. Review of Industrial Organization, 19(1), 55-69.

Malone, T. W. (1987). Modeling coordination in organizations and markets. Management Science, 33(10), 13171332.

Mantrala, M. K., \& Raman, K. (1999). Demand uncertainty and suppliers' return policies for a multi-store stylegood retailer. European Journal of Operational Research, 115(2), 270-284.

Marvel, H. P., \& Peck, J. (1995). Demand uncertainty and returns policies. International Economic Review, 36(3), 691-714.

Medina-Muñoz, D., \& García-Falcón, J. M. (2000). Successful relationships between hotels and agencies. $A n-$ nals of Tourism Research, 27(3), 737-762.

Medina-Muñoz, R. D., Medina-Muñoz, D. R., \& GarcíaFalcón, J. M. (2003). Understanding European tour operators' control of accommodation companies: Empirical evidence. Tourism Management, 24(2), 135-147.

Pan, C. M. (2007). Market demand variations, room capacity, and optimal hotel room rates. International Journal of Hospitality Management, 26(3), 748-753.

Parlar, M., \& Wang, Q. (1994). Discounting decisions in a supplier-buyer relationship with a linear buyer's demand. IIE Transactions, 26(2), 34-41.

Rosenblatt, M. J., \& Lee, H. L. (1985). Improving profitability with quantity discounts under fixed demand. IIE Transactions, 17(4), 388-395.

Tapper, R., \& Font, X. (2007). Tourism supply chains. Re- trieved August 13, 2007, from http://www.leedsmet. ac.uk/lsif/the/Tourism_Supply_Chains.pdf

Taylor, P. (1998). Mixed strategy pricing behavior in the UK package tour industry. International Journal of the Economics of Business, 5(1), 29-46.

Tepelus, C. M. (2005). Aiming for sustainability in the tour operating business. Journal of Cleaner Production, 13(2), 99-107.

Theuvsen, L. (2004). Vertical integration in the European package tour business. Annals of Tourism Research, 31(2), 475-478.

Tse, A. C. (2003). Disintermediation of travel agents in the hotel industry. International Journal of Hospitality Management, 22(4), 453-460.

Viswanathan, S., \& Wang, Q. (2003). Discount pricing decisions in distribution channels with price-sensitive demand. European Journal of Operational Research, 149(3), 571-587.

Wang, Q. (2002). Determination of suppliers' optimal quantity discount schedules with heterogeneous buyers. Naval Research Logistics, 49(1), 46-59.

Wie, B. W. (2005). A dynamic game model of strategic capacity investment in the cruise line industry. Tourism Management, 26(2), 203-217.

Wong, K. K. F., \& Kwan, C. (2001). An analysis of the competitive strategies of hotels and travel agents in Hong Kong and Singapore. International Journal of Contemporary Hospitality Management, 13(6), 293303.

Zhang, X., Song, H., \& Huang, G. Q. (2009). Tourism supply chain management: A new research agenda. Tourism Management, 30(3), 345-358. 